\title{
La emigración como es y como se recuerda
}

\section{AUTOR}

Víctor D.

Zamorano

Blanco*

vidazabl@hotmail.com

* Doctor en Historia por la

Universidad de Salamanca

\author{
A emigração como é e como é recordada
}

Emigration as Reality and as Remembered

\author{
GAMBI Giménez, Esther \\ La emigración castellano-leonesa a Brasil, 1946-1962 \\ Ediciones Universidad de Salamanca: Salamanca, 2012 \\ 196 páginas. ISBN: 978-84-9012-122-1
}

Las cosas no son como son, sino como se recuerdan. La feliz frase de Valle-Inclán que cita la autora en determinado momento de la introducción expresa bien la característica más destacada de este trabajo: la inclusión, en un riguroso y minucioso análisis histórico, de la perspectiva de los emigrantes en primera persona a partir de sus testimonios.

La autora coloca como objeto central de su trabajo a los emigrantes castellanos y leoneses que llegaron Brasil entre 1946 y 1962. Para ello, reconstruye un amplio contexto histórico que se extiende a lo largo de muchas más décadas y que abarca dos países distintos para poder comprender las diferentes facetas del fenómeno migratorio.

Las situaciones socioeconómicas española y brasileña, especialmente vinculadas al fenómeno migratorio; los marcos legislativos y políticos a ambos lados del mar; las dinámicas migratorias que precedieron esta oleada antes de la Segunda Guerra Mundial; los datos estadísticos puramente cuantitativos respecto al quién, el dónde, el cuándo, el cómo; y la memoria de los protagonistas, los emigrantes, recogida de forma oral; todo ello constituye el armazón sobre el que Esther Gambi profundiza en la realidad vivida por los castellanos y leoneses en Brasil y, sobre todo, en el São Paulo de la metropolización y el primer Pelé.

Cuando se habla de procesos migratorios en la historia contemporánea española tendemos a pensar en primer lugar en el periodo comprendido entre 1880 y 1930, no por nada conocido como de "emigración en masa". Se da por sabido que el siguiente gran salto migratorio español, el de época franquista, se dirigió predominantemente a Europa, y solemos ver a los españoles que emigraban como gallegos, vascos, asturianos, canarios. De ahí la necesidad de buscar en los resquicios que han dejado las mayorías. Así, aunque se le presta relativamente poca atención, hubo una importante emigración a América Latina en los años cincuenta y sesenta del siglo XX; y para colmo, desde Castilla y León a Brasil. 
Desde una perspectiva regional, los trabajos de Ricardo Robledo, García Zarza o Juan Andrés Blanco, entre otros, ya habían procurado exponer una Castilla y León que emigraba, y no sólo a las capitales interiores. En Brasil la presencia española, importante pero escurridiza, había llamado una atención mucho menor que otros colectivos nacionales, destacando al respecto los trabajos de Elda González. La emigración castellano-leonesa a Brasil es una muestra de una nueva ola de investigaciones centradas en idiosincrasias muy concretas que enriquecen nuestra perspectiva del panorama general de la historia de las migraciones.

La exploración de la reactivación de la corriente migratoria española (y más concretamente castellana y sobre todo leonesa) hacia Brasil tras la Segunda Guerra Mundial es la idea central en torno a la que gira el libro. Intentando resumir a pinceladas gruesas las principales conclusiones del trabajo, podríamos decir que León, Salamanca y Zamora predominan como focos emigratorios, dando fe de la buena salud de las cadenas migratorias conformadas en décadas anteriores; pero la autora identifica un leve aunque apreciable incremento en los aportes vallisoletanos y burgaleses. He ahí seguramente el aporte de obreros industriales que pretendía atraer Brasil; exiguo, ya que la emigración dirigida fue, según indica la autora, un completo fracaso como mecanismo de importación de mano de obra cualificada. La emigración castellano-leonesa sería de carácter familiar, poco cualificada y orientada al sector terciario.

Veremos cómo llega la autora a estas conclusiones analizando la estructura de la obra (muy clara, con títulos perfectamente descriptivos y contenidos pertinentes). El libro se divide en dos partes fundamentales. En la primera se da una visión general del recorrido histórico de la emigración de castellanos y leoneses a Brasil en dos capítulos: un primero sobre los antecedentes (la emigración masiva), y un segundo recreando los marcos históricos, sociales y económicos brasileño y español de la que llama la "segunda oleada". En la segunda parte se tratan en profundidad los emigrantes españoles en Brasil entre 1946 y 1962 conjugando una perspectiva macro y una aproximación al detalle más pequeño: recorre las causas de su emigración, los diferentes tipos de emigrantes y presenta un análisis cuantitativo del fenómeno.

Repasando las principales claves de la emigración en masa, Esther Gambi intenta tanto exponer los orígenes de la segunda oleada como obtener un término de referencia y comparación. Demuestra conocer bien la literatura científica sobre las causas de la emigración, sometiendo las teorías pushpull y las "causas habituales" a un duro enfrentamiento con la realidad específica de la Castilla y León del momento: particularidades de la estructura agraria, la dinámica de los arrendamientos de tierras y el precio del trigo, la crisis agraria.

El repaso a la emigración en masa se completa con una visión panorámica del Brasil que encontrarían los inmigrantes castellanos y leoneses de la edad de oro de los cafetales. En general, se comportaron como los demás españoles (es decir, emigraron como familias agrarias subvencionadas y fueron principalmente a los cafetales del interior del estado de São Paulo, aunque puede encontrárseles entre los españoles en otros destinos minoritarios). También hace especial hincapié en la presencia de estos inmigrantes en el movimiento obrero y en el contexto de la Guerra Civil Española vivida desde Brasil.

Tras el parón migratorio generalizado de la Segunda Guerra Mundial, los panoramas español y brasileño y sus legislaciones sobre migración se preparan para la nueva generación de migrantes. Es el contexto histórico de la segunda oleada. Un Brasil en pleno desarrollismo busca trabajadores industriales cualificados de forma constante a pesar de los vaivenes políticos que sufre; a una Castilla y León empobrecida entre la autarquía y el desarrollismo no le viene mal aliviar un poco de presión social facilitando la salida de población y la entrada de divisas. 
En la segunda parte de la obra (capítulos 3 al 5) la autora entra de lleno en el meollo del asunto: las causas (las más específicas), los tipos de migrantes y características de los castellanos y leoneses en Brasil. Podemos destacar que la emigración por causas políticas no fue demasiado relevante; más bien el estancamiento económico de la región y el efectollamada desplegado por las redes migratorias hicieron el trabajo en el lado español. Al otro lado del mar, el esfuerzo publicitario y político de las autoridades brasileñas hizo el resto para reactivar la emigración de castellanos y leoneses a Brasil.

En cuanto a la tipología, Gambi desmenuza la emigración dirigida y la espontánea, valorando las cifras y sobre todo señalando el tremendo coladero que supusieron los filtros brasileños para obtener trabajadores industriales y la tibieza de control, cuando no abierta promoción, de las autoridades españolas para facilitar la salida de emigrantes a Brasil (sobre todo a través de los programas de reagrupación familiar). La autora dedica asimismo un pequeño espacio a la emigración clandestina, mostrando cómo los emigrantes hacían de la necesidad virtud y se aprovechaban, bordeando la legalidad, de las facilidades ofrecidas por Brasil. También explora dos tipos muy particulares de emigración, los misioneros católicos y las migraciones colectivas.

Para exponer las características de los castellanos y leoneses en Brasil, la autora se embarca en un análisis cuantitativo de las escasas fuentes estadísticas de que se dispone; demostró una gran agudeza explotando al máximo las informaciones contenidas en las solicitudes de visados en el consulado español de São Paulo, principal foco de atracción de españoles y castellano-leoneses. Tras explicar los volúmenes a lo largo del tiempo y compararlos con los principales países receptores del entorno, se adentra en las peculiaridades del caso brasileño: el destino (São Paulo acapara más de la mitad de la corriente, seguido a distancia por Río de Janeiro, Salvador de Bahía y otros destinos), la procedencia (básicamente las provincias del antiguo reino de León) y la composición (muy familiar, con muchos menores y mujeres dedicadas al trabajo doméstico, y "sólo" un 38\% de obreros cualificados) de la corriente castellana y leonesa; de donde extrae las interesantes conclusiones que ya hemos visto.
El primer acierto de este trabajo es la utilización de las fuentes. Lejos de aferrarse a ellas, la autora hace una excelente crítica de las fuentes estadísticas, con la honestidad de no refugiarse en un puñado de datos (si esto es lo que hay, es lo que hay) pero sin dejar de analizarlas hasta encontrar informaciones útiles para la investigación. Debería ser innecesario decirlo, pero el uso de fuentes y también de bibliografía, tanto españolas como brasileñas, es fundamental para obtener una visión con al menos dos caras de una misma realidad. En este sentido, la autora ha recurrido a multitud de fuentes de origen diplomático y policial en los archivos de Itamaraty y los estados de São Paulo y Río de Janeiro en Brasil; y en el archivo del Ministerio de Asuntos Exteriores español.

Demuestra conocer bien la bibliografía española contemporánea (la de los Sánchez-Albornoz, Eiras Roel, Núñez Seixas, Sánchez Alonso) y los trabajos brasileños imprescindibles (González, Klein, SouzaMartins, María da Souza, José do Nascimento, Elena Peres, Avelina Gallego y muchos otros), y también esa rica bibliografía generada por los contemporáneos del fenómeno. Y no sólo la específicamente relacionada con las migraciones o con la historia; el fondo bibliográfico utilizado es muy amplio, algo fácilmente apreciable en la contextualización.

Esther Gambi hace un notable esfuerzo a la hora de definir su objeto de estudio y el tratamiento que le da "cubre" bien el tema y es adecuado. Plantea un hilo argumental claro y coherente. Desciende a niveles de explicación a veces muy micro, que ofrecen una comprensión distinta de las vicisitudes de los emigrantes. El análisis pormenorizado de un volumen muy concreto de fuentes permite afinar el análisis, por ejemplo a la hora de evaluar de cerca las causas de la emigración señalando un factor como la influencia de una campaña publicitaria específica, o las expectativas salariales de los por otro lado poco cualificados inmigrantes españoles como motivo de la movilidad laboral contante. Factores que generalmente se pasan por alto en una perspectiva macro, pero que pueden resultar determinantes a escala individual.

Pero la principal fortaleza de esta investigación es la historia oral, el testimonio, que la autora utilizó con más profundidad en su tesis doctoral 
a través de entrevistas semi-estructuradas a castellanos y leoneses que emigraron a Brasil. Utiliza con maestría esa baza: incluir la perspectiva subjetiva en el análisis histórico. Consigue un buen equilibrio entre los datos cuantitativos oficiales y las percepciones individuales de los migrantes. Y abre un espacio para contemplar los eventos personales, lo único, lo no sistemático, que tanto enriquece nuestra observación del pasado.

Además, el libro está muy bien escrito, expresando las ideas con una claridad que facilita su asimilación, de una manera tan fluida que parece sencillo hacerlo. Valgan como ejemplo sus reflexiones acerca de las causas de la emigración; puede parecer poco señalar como idea central que las causas con complejas, pero Esther Gambi completa esa idea aparentemente simple (que no debe perderse nunca de vista) con pequeñas pinceladas de realidad muy pertinente y con un resultado coherente.

Toda obra tiene sus peros. Seguramente por necesidades de la edición, la primera parte del trabajo, la contextualización, es muy amplia en comparación con la segunda, en la que se echa de menos una atención todavía más pormenorizada al cotidiano de los inmigrantes. La reflexiones en torno a la causalidad de la migración (de nuevo las causas) aparecen repartidas en distinta partes del libro, pues son un factor importante y complicado y es difícil presentarlo en un orden absoluto. Por último, la predominancia cuantitativa de la inmigración paulista se impone en este trabajo, algo lógico por otra parte, pues como ya señalaban los estudios de los pioneros como Elda González o Herbert Klein, aquel era de largo el principal centro receptor. Insistiendo en la idea de conocer mejor las corrientes minoritarias, la presencia española en los estados del sur de Brasil y en el Pará sigue aguardando análisis más profundos.

La emigración castellano-leonesa a Brasil demuestra lo que se puede hacer cuando se dejan a un lado los grandes volúmenesy se presta atención al resto. En ese sentido, Gambi saca oro de las piedras: un excelente trabajo historiográfico sobre un colectivo minoritario, con datos relativamente escasos (y seguramente por ello, poco llamativo), que contribuye a nuestro mejor conocimiento y comprensión de las migraciones españolas en general. 